
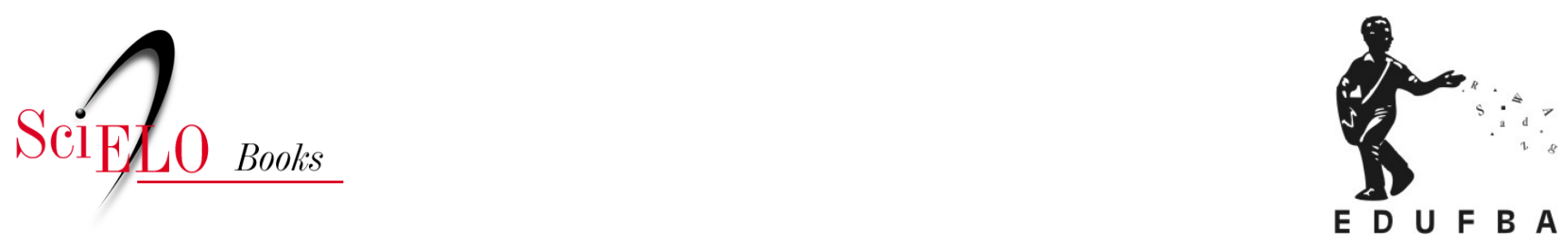

\title{
Cenas musicais e estilos
}

\author{
Luciana Xavier de Oliveira
}

\section{SciELO Books / SciELO Livros / SciELO Libros}

OLIVEIRA, L. X. Cenas musicais e estilos. In: A cena musical da Black Rio: estilos e mediações nos bailes soul dos anos 1970 [online]. Salvador: EDUFBA, 2018, pp. 29-54. ISBN: 978-85-232-1872-0. https://doi.org/10.7476/9788523218720.0002.

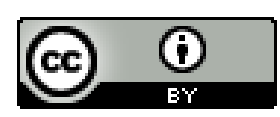

All the contents of this work, except where otherwise noted, is licensed under a Creative Commons Attribution $\underline{4.0 \text { International license. }}$

Todo o conteúdo deste trabalho, exceto quando houver ressalva, é publicado sob a licença Creative Commons Atribição 4.0. 


\section{Cenas musicais e estilos}

A noção de cena musical tem sido bastante debatida no Brasil, especialmente na produção acadêmica de pesquisadores da área de comunicação. ${ }^{1}$ De fato, o conceito é egresso do próprio jornalismo musical e tem sido alvo de pesquisas importantes de teóricos dos estudos culturais (BAULCH, 2003; BERGER, 1999; KAHN-HARRIS, 2000; STRAW, 1991), que passaram a utilizar o termo como ferramenta conceitual em substituição à noção de subculturas ou de comunidades musicais. A ideia de cena foi desenvolvida no sentido de ajudar a interpretar um conjunto de práticas sociais, econômicas, tecnológicas e estéticas em torno do consumo da música popular massiva nos ambientes urbanos. (JANTOTTI JUNIOR; PIRES, 2011, p. 11) A noção de cena ainda aponta para "uma ambiência social, onde os objetos, ruas, clubes, bares, equipamentos, aparelhos, prédios e palcos formam um contexto material para as interações culturais entre indivíduos e grupos”. (TROTTA, 2013, p. 59) A cena musical, pois, pode ser uma importante ferramenta para a compreensão do consumo da música no ambiente urbano, indo além de questões restritas à sonoridade para abarcar territórios, circulação de produtos e sociabilidades.

1 Ver: Janotti Junior (2012a), Sá (2011), Freire Filho e Fernandes (2005) e Pires (2011). 
Outro ponto importante levantado pelas recentes discussões desenvolvidas no campo da comunicação a respeito da noção de cena musical refere-se a reflexões que se detêm sobre a relação entre cenas, consumo cultural e representação. A vinculação da cena musical a questões envolvendo processos de identificação tem sido frequente no Brasil, especialmente em trabalhos acadêmicos cujo objeto é o manguebeat. ${ }^{2}$ A discussão também tem apresentado outros desmembramentos mais recentes, em trabalhos que fazem referência às cidades e aos espaços urbanos a partir da ação de culturas juvenis que se estruturam em torno de práticas musicais, incluindo aí as comunidades virtuais e redes sociais, que trazem para a questão a ação das novas tecnologias de comunicação. Esse cenário evidencia a importância da ideia de cena acionada por diferentes autores na investigação de objetos variados. (BAULCH, 2003; BERGER, 1999; JANOTTI JUNIOR, 2012a; KAHN-HARRIS, 2000; STRAW, 2006) Esses trabalhos abordam as cenas musicais a partir das condições de produção e circulação midiática e mercadológica dos produtos musicais, enfatizando a ação cultural e o exercício estético de fãs, artistas, produtores e indústria fonográfica. Mas nem sempre privilegiam os processos de representação sociocultural e as dinâmicas subjetivas da experiência e do consumo musical, que podem agenciar sociabilidades e identidades culturais marginais e/ou alternativas.

Pioneiro no estudo das cenas musicais, Will Straw vem desenvolvendo importantes reflexões desde os anos 1990. Para ele, as cenas podem ainda se referir à reunião de pessoas em um lugar, bem como ao movimento delas, englobando diversos espaços e atividades realizadas ao redor de uma preferência cultural-musical específica, estabelecendo redes de atividades microeconômicas e sociabilidades que relacionam a cena à fruição da cidade. (STRAW, 2006, p. 6) Ainda segundo Straw (2006), as cenas também podem se referir a um fenômeno maior e mais disperso geograficamente, mas que se articula também em movimentos locais, como no caso do heavy metal, que possui variadas manifestações em diferentes regiões do globo. A circulação da música ainda pode incluir os fluxos on-line na configuração de cenas virtuais em

2 Ver: Ribeiro (2006) e Lima (2007). 
territórios informacionais, como no caso da comunidade de fãs de música eletrônica. (THORNTON, 1996)

O objetivo de Straw ao trabalhar com o conceito de cena era construir uma proposta interpretativa para a compreensão das práticas musicais na cidade, que transformam clubes, ruas, bares, praças e casas noturnas em territórios culturais demarcados por fronteiras geográficas e processos de diferenciação, materializando diversos envolvimentos afetivos e experiências em diferentes culturas musicais. O conceito de cena musical, até então, já era amplamente utilizado pela imprensa musical e foi sistematizado por Straw em trabalhos consecutivos como uma visão alternativa à ideia de subculturas urbanas, trabalhada por autores como Dick Hebdige (1979) e Paul Willis (1978).

Os estudos subculturais, apesar de oferecerem importantes contribuições à compreensão das dimensões estéticas da cultura popular juvenil, acabaram por deixar algumas lacunas na reflexão sobre formações de alianças afetivas vinculadas à expressão musical. Esses autores correspondiam à tendência acadêmica engajada dos cultural studies dos anos 1960 e 1970, cujas teorias eram marcadas por um compromisso crescente com questões políticas. O Centre for Contemporary Cultural Studies da Universidade de Birmingham, na Inglaterra, pretendia promover estudos e pesquisas interdisciplinares sobre novas práticas culturais com um viés neomarxista, com o propósito de "habilitar e encorajar os estratos subordinados a resistir à opressão e a contestar ideologias e estruturas de poder conservadoras”. (FREIRE FILHO; FERNANDES, 2005, p. 1) Nesses estudos subculturais iniciais, havia uma proposta de compreender esses grupos como uma manifestação legítima da vida juvenil, analisando como os estilos de vida, espaços territoriais e artefatos da cultura de consumo eram utilizados de forma crítica, espetacular e criativa diante das instâncias hegemônicas dominantes da sociedade. No entanto, essas visões passaram a receber críticas de novos autores a partir dos anos de 1990, que denunciavam o conceito de subculturas como algo datado diante da profusão de estilos, formas e práticas culturais contemporâneas, mais voláteis e movediças, esvaziando seu sentido original. A noção de subcultura também foi criticada por excluir de suas abordagens questões como raça e gênero, privilegiando a classe como aspecto central em sua definição. 
Outro problema do debate subcultural era sua falta de aprofundamento da discussão do próprio funcionamento do consumo musical na formação e desenvolvimento das culturas juvenis, o que poderia ampliar a reflexão sobre experimentações e configurações criativas das identidades, performances e linguagens.

Nesse panorama, a ideia alternativa de cena musical parece mais adequada, pois dá conta da formação das redes de lazer, gosto, criatividade e identidade que estruturam a relação entre as culturas juvenis e a música popular massiva, sinalizando para a importância do consumo cultural como uma via de construção de alianças que se estabelecem para além das tradicionais disputas por hegemonia. A noção de cena também assinala a coexistência de diferentes práticas musicais que interagem entre si, dinamizando variados processos de diferenciação e cross-fertilizations estimulados pela circulação global de formas culturais, como aponta Straw (1991), favorecendo a construção de novos valores, símbolos e gêneros musicais. É nesse contexto que a internacionalização pode produzir uma diversidade mais complexa, ao invés de impor uma homogeneização nas dinâmicas da música popular massiva. Não obstante, ainda é possível perceber certa coerência no interior desses espaços, ancorada justamente em um território, o que dá ao local geográfico privilégio na garantia da continuidade histórica de estilos, gêneros e práticas musicais (CARDOSO FILHO; OLIVEIRA, 2013), definidos tanto pelas ações dos agentes sociais da cena, como também pelos processos de subjetivação articulados às próprias fronteiras culturais. Portanto, para compreender as cenas em um sentido mais produtivo, é interessante percebê-las com processos que se desenvolvem e se reconfiguram na história, tomando corpo na sociedade de maneiras difusas, mas coerentes, a partir de interesses, práticas, compromissos, identidades e aspirações distintos.

Em suma, os estudos aqui elencados utilizam a ideia de cena a partir de alguns princípios norteadores, como a conexão entre cena e um território geográfico, como um bar, uma rua, um clube, uma discoteca; a cena vista como um território pautado pelo consumo cultural cosmopolita de gêneros musicais; e a cena como um espaço simbólico voltado para constituição subjetiva de processos de identificação cultural e performances de gosto. É também importante manter em vista a noção de que cenas musicais implicam fluxos 
desiguais de produção e circulação de artefatos culturais, formando segmentos paralelos e independentes, mas que podem estar em constante tensão com um mercado mainstream. Esses processos reflexivos que estabelecem e também são estabelecidos por relações, afetos e comprometimentos em torno da música, fluidos, efêmeros e variáveis, mesmo mantendo uma coerência em um espaço urbano, são ainda capazes de se repetir em outros locais, de outras maneiras, para além ou aquém de uma institucionalização que, por exemplo, o conceito de circuito cultural propõe. A ideia de cena musical aborda maiores complexidades, resultantes de deslocamentos dos sujeitos e repertórios culturais, cujas expressões são acionadas nos discursos, nos gostos performatizados e nos estilos, além do que no estabelecimento de redes concretas de circulação e consumo. Pois as cenas, enquanto redes complexas de lazer, solidariedade e sociabilidades, se constituem a partir da própria experiência de escuta e fruição musical e, enquanto topologia constitucional e semântica, correspondem às situações vividas em uma sociedade de consumo, marcadas pela cultura popular massiva e pelas constantes mutações inerentes a uma conjuntura globalizada.

\section{Cenas, identidades e consumo cultural}

As cenas musicais consolidam múltiplas alianças coletivamente a partir de experiências materializadas e valores compartilhados. Esse processo se configura mediante expectativas, sugestões e projeções que, mesmo que ainda não conscientemente percebidas, se tornam visíveis ao estruturar experiências anteriores, imprecisas, voláteis e dispersas em um espaço que institui novos horizontes de expectativa. A cena musical, pois, não se trata de um conceito que classifica uma experiência, mas ela própria cria experiências por meio da ação de seus próprios participantes, cujas experiências sensíveis determinam os sentidos particulares que emergem de cada cena musical, demarcando fronteiras de um autorreconhecimento dinâmico correlacionado a instâncias produtivas e atos reflexivos de consumo.

Nessas dinâmicas, música e identidade não estão isoladas e se materializam em territórios simbólicos que são configurados justamente por meio da performatização de gostos, valores e afetos. Afeto no sentido dado por 
Sovik (2009, p. 51), de abertura não verbal para o mundo, realizada na consciência dos sujeitos no entorno, que passa pela compreensão da realidade para além dos discursos e narrativas. É esse momento, quando "os relatos ainda não foram estabelecidos”, que torna mais potentes os relacionamentos, as ações grupais e o engajamento com o outro. Assim, entendo que as cenas musicais são fenômenos marcadamente cosmopolitas, pautados pelo consumo cultural e por estratégias simbólicas de diferenciação, em que seus participantes são constantemente afetados pela relação com os outros, com os objetos e com a sociedade, estabelecendo novas maneiras de relacionamento com a alteridade. Essas culturas de consumo da música efetivadas nas negociações e apropriações culturais, bem como em práticas de consumo mundializado, ampliam, pois, a própria noção de identidade cultural, não mais centrada em nações, línguas, fronteiras, desestabilizada por processos de migrações de pessoas, bens e símbolos.

Essa concepção de identidade cultural se refere a um constructo social de caráter relacional e contingente, que difere de um contexto para outro, expresso por processos individuais e coletivos de reconhecimento e autorreconhecimento. Nessas dinâmicas, são estabelecidas relações sociais e simbólicas, de valores e hábitos compartilhados por um determinado grupo. As identidades seriam, pois, dotadas de mobilidade, já que são constantemente afetadas pela história e pelas condições contemporâneas das sociedades, da mesma forma que pelas dinâmicas locais e globais. No entanto, como afirma Gilroy (2001), a identidade não é um conceito fixo e transcultural, pois mantém certa coerência no tempo e no espaço, sendo mobilizada de acordo com determinadas circunstâncias pelos indivíduos. Ao mesmo tempo, Hall (2003) aponta que uma identidade totalmente unificada e coerente é uma fantasia, pois ela é permanentemente confrontada pela multiplicidade de sistemas de significação e representação cultural. Assim, ela seria efetivamente determinada pelo conjunto de papéis que são performatizados nas interações sociais e também pelas condições decorrentes da produção da vida material, sempre em processo de mutação, da mesma forma que são todos os processos culturais, seguindo uma visão crítica da cultura.

Com efeito, o caráter móvel, híbrido e contingente das identidades nas cenas musicais já era apontado por Straw em 1991, numa conferência que 
deu origem ao artigo "Systems of articulation, logics of change". Nele, o professor canadense sistematiza a noção de cena musical e critica o conceito de comunidade utilizado por pesquisadores de estudos culturais, dotado de uma pretensa uniformidade. Straw (1991) defendia que as cenas inferiam em uma gama de práticas musicais projetadas sobre um território, conectadas à sobreposição de experiências subjetivas materializadas em torno da música. Havia também uma crescente influência, dentro da teoria cultural, que tendia a um engajamento em conceitos como território e nação. Uma preocupação que acompanhava as discussões em torno da autenticidade dentro dos estudos de música popular, mas que acabava por engessar as reflexões e o próprio conceito de identidade cultural.

Se as cenas musicais, como qualquer outra instância da cultura popular, representam zonas de tensão na definição de significados e valores não apenas musicais, mas subjetivos, elas inscrevem também diferentes formas de sociabilidade, solidariedade e processos dinâmicos de identificação em núcleos coerentes e particulares de atividade social e cultural. Aqui, a noção de identidade ou os processos de identificação oferecem um dispositivo interpretativo importante para pensarmos sobre as interrelações entre individualidade, comunidade e solidariedade. (GILROY, 2007, p. 123) As identidades são a chave para entender a interação entre experiências subjetivas e cenários histórico-culturais e são "construídas dinamicamente, dentro do grupo e na interação com os outros grupos, por meio de elaborações e reelaborações permanentes”. (DOMINGUES, 2009, p. 4) Já a noção de cena musical possibilita compreender a formação de espaços de ligação entre identidade, territórios, temporalidades contingentes e sonoridades, estabelecendo zonas simbólicas disjuntivas para populações deslocadas (minorias, imigrantes, colonizados), entrelugares de interseções e diferenças transitórias diante de culturas hegemônicas.

O consumo da música, nesse contexto, aponta para uma fundamental e profícua maneira de expressar a cidadania e a identidade, ao se recompor em circuitos desiguais e mutáveis de produção, comunicação e apropriação cultural. (GARCÍA CANCLINI, 2007, p. 137) As cenas musicais, entendidas aqui como fenômenos midiáticos que atualizam traduções e hibridizações criativas, “[...] ganham mais peso que os tradicionais locais na transmissão de 
informações e imaginários sobre a vida urbana e, em alguns casos, oferecem novas modalidades de encontro e reconhecimento". (GARCÍA CANCLINI, 2007, p. 159) O consumo musical, nessa esfera, ganha status de experiência social e apropriação coletiva de objetos mundanos que assumem novo valor, estruturando relações de solidariedade e distinção que deixam explícito um "exercício refletido de cidadania” (GARCÍA CANCLINI, 2008), especialmente em contextos de desigualdade e exclusão. Seguindo essa perspectiva, concordo que o consumo de bens, produtos culturais e informações comunicacionais tem oferecido mais respostas do que os meios tradicionais de representação política e que as abstrações das democracias claudicantes não oferecem, no contexto dos países em desenvolvimento, um instrumento suficiente e adequado para a superação das injustiças sociais.

Como parte de um fenômeno integrativo e comunicativo das sociedades contemporâneas, o consumo cultural afirma a "simbolização e o uso de bens materiais como comunicadores, não apenas como utilidades”, de acordo com Featherstone (1995, p. 121). Seguindo essa visão, o mundo das mercadorias, a cultura de consumo e seus princípios de estruturação são organizados em meio a tendências globalizadoras, centrais para o entendimento da sociedade contemporânea. O consumo, portanto, concretiza a manifestação de sujeitos e identidades que interagem entre si em uma experiência coletiva de apropriação e uso de produtos culturais em meio a diferentes processos sociais. $\mathrm{E}$ é na diversificação de gostos e estilos que se torna possível o acesso às bases estéticas que vinculam democracia à cidadania.

Na vida quotidiana, o consumo é moldado pela estrutura material e simbólica dos espaços geográficos, pelas desigualdades, pelos modos de vida, valores, estilos e também por transformações sociais. (MCCRACKEN, 2003) Os consumidores organizam as sociedades usando os significados dos bens de consumo para expressar categorias e princípios culturais identitários. O consumo passa a ser simbólico e destaca a dimensão social dos produtos e das ações de consumo, também promovendo relações entre indivíduos e experiências diversas. O consumo cultural é, assim, configurado por códigos e práticas do dia a dia que elaboram classificações, reafirmam diferenças e modulam comportamentos que estão em constante tensão com ideologias de mercado e estratégias interpretativas distintivas. 
Compartilhar identidade é estar vinculado fundamentalmente à formação de padrões de pertencimento, através de conexões subjetivas e alianças afetivas instáveis, movediças e contingentes. Essa partilha articula os sujeitos não apenas a uma unidade coerente - como ao território significativo da cena musical -, mas também cria vínculos interpessoais. Nesse sentido, apesar de não ser algo recente, o pensamento que conecta a identidade ao território pode ser também útil para a compreensão das relações de afeto e pertencimento que unem uma comunidade de fãs a uma cena. Essa ligação simboliza também a relação da consciência, da experiência e da sensibilidade com o território, que possui implicações políticas, culturais e sociais. A cena oferece, pois, um território para a afirmação de laços emocionais e afetivos, além de traços culturais divergentes e marginais que se concretizam em atividades sociais e em espaços de compartilhamento de afinidades e identidades.

A ideia de cena musical, desse modo, oferece um instrumento importante para compreender os laços afetivos entre indivíduos e a música e como essa relação transforma os espaços urbanos e contextos sociais. As práticas sociais de configuração e ocupação de territórios significativos engendradas nas cenas incluem os indivíduos nos processos de criação, distribuição e circulação musical, que envolvem relações sociais e econômicas. (PIRES, 2011, p. 4) Esses processos também são formulados a partir de manifestações da diferença, que ultrapassam hierarquias e binarismos fixos da alteridade, em estreita relação com uma reflexão ética sobre as identidades culturais, inscritas em processos contingentes, dinâmicos e instáveis de negociação.

As identidades culturais, longe de polaridades fixas, podem ser interpretadas como mobilidades reflexivas, câmbios e hibridações que criam formas diferentes de saberes alternativos, que se infiltram no discurso dominante e embaralham suas regras de reconhecimento. Em relação a essa dinâmica, Bhabha (1998, p. 165) propõe uma substituição da ideia de diversidade cultural pela noção de diferença cultural. Suas reflexões apresentam uma perspectiva da diferença enquanto processo da enunciação, que constrói sistemas múltiplos de identificação cultural a fim de criar um espírito mais produtivo da alteridade. A partir dessa perspectiva crítica, a compreensão da diferença cultural assume um caráter discursivo, visto que toda cultura é uma forma de atribuir significado a um mundo circunscrito em termos temporais e 
geográficos. Diante da negociação da diferença, o que está em jogo são tradições culturais e hábitos internalizados e cristalizados que, em instâncias mais profundas, constroem significados sobre as diferenças em territórios simbólicos. Assim, diferença e negociação caminham juntas e ultrapassam mecanismos simples de apropriação, já que o outro é da ordem do indefinível, do incomensurável, que negocia com as alteridades e se constitui "na estreita passagem do entrelugar do discurso do enraizamento e do afeto do deslocamento". (BHABHA, 2011, p. 153) O entrelugar, para Bhabha (2011), é o ponto de gestação e mutação de subjetividades híbridas, que negociam entre si em sua ambiguidade, contradição e ambivalência. É o limite epistemológico e fronteira enunciativa para uma gama de outras vozes subalternas na instituição de novas redes de poder, realçando a natureza performativa das identidades e da diferença e a negociação de espaços, fronteiras e limites da diferença, em instâncias como a classe, gênero ou raça.

De acordo com essa ordem performativa das identidades, a representação da diferença não se reflete em traços culturais ou étnicos preestabelecidos, inscritos em tradições fixas. Sua articulação social, especialmente em se tratando de minorias, passa por negociações e diálogos complexos e contextuais, mas que não retiram a legitimidade dos hibridismos culturais que surgem em momentos de transformação social e histórica. Essa relação instável e fluida entre identidades e entre espaços é o que nos permite compreender a cena musical em seu caráter movediço e permanentemente indeterminado por ciclos circunstanciais, próprios das mutações do espaço urbano. As cenas seriam fendas em territórios fronteiriços, pontos de encontro e também de desconstruções discursivas - uma espécie de "terceiro espaço" (BHABHA, 1996) - que conferem às produções culturais e identidades performatizadas nesse território sentidos nunca totalmente transparentes. Esse terceiro espaço é o espaço instigante e privilegiado da negociação cultural, lócus legitimamente gerador de hibridismos, que desconstrói "a fantasia da origem e da identidade fixa” (BHABHA, 1998, p. 106), negando ou recriando autoridades ao perturbar ordens estabelecidas pelas mesclas inconclusas e insubordinadas de subjetividades.

Recusando uma homogeneidade opressiva, essas vozes marginais fazem da diferença uma força cultural que legitima publicamente o caráter político 
de suas identidades, que estão fora do alcance da fixidez de tradições e estereótipos. Se o consumo deve ser compreendido como um sistema de significação que supre necessidades simbólicas, ele funciona, pois, como código a partir do qual as relações sociais e subjetivas são construídas. (ROCHA; BARROS, 2008) Dessa forma, o status simbólico e material dos produtos midiáticos pode ser uma fonte geradora de um código cultural para essas alteridades, estabelecendo alianças provisórias e, por vezes, contraditórias, com a finalidade de aumentar sua força reivindicatória dentro de processos permanentes, heterogêneos e mutáveis.

Assim, a cena musical apresenta-se, nessa perspectiva, como uma "comunidade cosmopolita vista como uma marginalidade” (BHABHA, 2011, p. 145), um ambiente de reconhecimento de diferenças negadas em outras esferas hegemônicas sociais e culturais. Ao mesmo tempo em que oferece um espaço para identificações afetivas, a cena musical é um território de travessia entre diversos meios sociais, local de encontros e experiências intersticiais que instauram um patamar intermediário entre o indivíduo e a sociedade. Atuando como espaço de celebração de alianças e sobrevivências de singularidades ligadas a memórias trans-históricas e estruturas representacionais, sempre provisórias. Nesse ponto, articulo o posicionamento de Bhabha ao conceito de estruturas de sentimento, de Raymond Williams, que reivindicava uma reflexão estética menos formalista e mais próxima da vida cotidiana. A discussão preliminar da ideia de estruturas de sentimento está em Marxismo e literatura (1979), em que Williams articula historicidade e cultura, pensando nas formas como surgem novas consciências a partir das rotinas, destacando um enfoque sobre os processos ativos dos sujeitos na produção do sentido. (CARDOSO FILHO, 2014, p. 73) É no cotidiano que os participantes das cenas musicais se articulam para tecer narrativas, construir novas ações culturais e estabelecer diferentes disposições afetivas. Nesse contexto, as cenas seriam constituídas também como espaços de experiências, memórias e afetos, estabelecendo novos valores para os produtos midiáticos à disposição. Essas experiências concretizadas no território ressignificam tanto os atos de consumo cotidianos quanto a própria vida nas cidades, de maneiras alternativas e criativas. 
Nessa proposta, as cenas implicam um sentido ético, direcionado para as condutas em sociedade, e dimensão estética, que constrói uma sensibilidade comunitária, em permanente negociação com seus variados atores. As cenas são assim compreendidas como fenômenos estéticos, pois moldam e são moldadas por afetos, valores, formas de sentir e de perceber o mundo. E são práticas expressivas dotadas de força política, porque o consumo cultural, as performances e os estilos podem "(re)posicionar os sujeitos em processos distintos de partilha, criando competências diferentes nas esferas públicas do cotidiano”. (CARDOSO FILHO, 2014, p. 75)

É importante, por isso, aproximar o estudo das cenas musicais e das práticas culturais de grupamentos juvenis à questão estética e política, o que pode auxiliar na compreensão de determinadas posturas de resistência e de formas de negociação de posições estratégicas, que configuram ações políticas tomadas por afetos e emoções. Esses aspectos baseiam as estruturas de sentimento que possibilitam o surgimento de novas consciências e estilos de vida, dotados de um explícito gesto político que torna público um pensamento e uma experiência sensível. E ainda dá sentido ao consumo de objetos simbólicos e à ocupação de um espaço que acompanha a própria formação de uma comunidade, utilizando a mídia e a música popular massiva como espaço fundamental de negociação de representações políticas e experiências subjetivas.

\section{Percursos metodológicos}

No conjunto dos estudos das cenas, é notável a frequência de alguns tipos de percursos metodológicos realizados por autores de diferentes áreas do conhecimento. Autores de diversas áreas utilizaram diferentes procedimentos metodológicos em seus estudos sobre cenas musicais. Para analisar aspectos identitários de grupos de ouvintes da música eletrônica contemporânea, Thornton (1996) fez uso da observação participante e da etnografia em clubes e bares. Com o objetivo de identificar características singulares de uma cena específica local em relação à expressão global do gênero musical, Cardoso Filho (2008) realizou procedimentos como a interpretação textual de produtos e performances a partir da análise semiótica de discos e/ou das letras de heavy metal. Já autores como Kahn-Harris (2000) se propuseram a 
produzir análises textuais articuladas à pesquisa das condições de produção e reconhecimento do gênero musical dentro da cena, bem como recorreram a traços biográficos dos músicos, seguindo uma perspectiva da sociossemiótica a fim de dar conta de traços sociais mais complexos, articulando dimensão textual quanto aspectos contextuais.

Em "Systems of articulation, logics of change", Straw (1991) deixou poucas indicações metodológicas a respeito de como apreender uma cena, privilegiando a construção de uma proposta interpretativa para a compreensão do termo que, segundo o autor, se remete à materialização de práticas musicais em um território cultural demarcado por fronteiras geográficas e de valor que contribuem para um envolvimento afetivo na cultura musical. Nesse texto, Straw comparou as cenas do rock pós-punk e da dance music, configurados por lógicas de transformação e sistemas de articulação entre contextos locais e globais. Na descrição das cenas, no entanto, o autor não apontava métodos específicos e, basicamente, as fontes nas quais fundamentou suas considerações foram compostas por textos teóricos específicos sobre música pop e por dados divulgados em publicações periódicas, como a revista Billboard ou The Wall Street Journal, fontes primárias disponíveis à época dos objetos de estudo trabalhados.

Harris M. Berger (1999) desenvolveu seu estudo partindo do pressuposto de que a música se caracteriza por possuir uma dupla natureza na sua prática: a experiência pessoal e a cena como um grupo social. $\mathrm{O}$ autor trabalhou tanto com os agenciamentos e ações dos sujeitos envolvidos na prática musical (intenções em expressar algo, ideologia etc.) quanto com os dispositivos sociais de regulação impostos pelo grupo social (como o tipo de bebida mais consumida, as regras de comportamento, a forma de dança). Nessa pesquisa, o autor, como observador participante, realizou três etapas metodológicas: uma etnográfica, na qual observava as práticas de sociabilidade dos integrantes da cena; uma etapa de descrição da experiência musical, tanto em seus aspectos de sentido quanto estéticos, para a qual Berger registrou shows e entrevistou músicos, buscando coletar mais dados sobre a relação que se estabelecia entre os ouvintes e a própria música; e um momento de análise da relação entre local e global dentro daquela cultura musical. 
Para Kahn-Harris (2000), o estudo da dicotomia entre local e global na cena de metal extremo foi efetivado a partir da análise da trajetória da banda brasileira Sepultura, enfocando mais especificamente a produção do álbum Roots (Roadrunner Records, 1996), no qual a banda traz referências sonoras, temáticas e linguísticas da cultura brasileira. Kahn-Harris recorreu tanto aos aspectos biográficos da banda quanto a análises de canções e das condições de produção, no início da carreira e no período de confecção de Roots, tentando articular tanto a dimensão textual quanto os aspectos contextuais que configuram a tensão local versus global na música da banda. Procedimento semelhante foi adotado por Janotti Junior (2012b), que retomou a análise das cenas musicais de heavy metal, tomando como objeto de estudo uma música também da banda Sepultura, "War for territory". Questionando as experiências que se sobrepõem nas diferentes mediações da vida social e da cena musical, o autor analisou letra e aspectos sonoros da canção, compreendendo-a como manifestação da tensão em torno da construção de alianças afetivas no território sonoro do heavy metal, também realizando entrevistas com músicos e críticos culturais.

No caso de cenas musicais distantes historicamente dos próprios pesquisadores, passadas, arcaicas e/ou residuais, mas com as quais ainda temos experiência de alguma maneira na cultura contemporânea, não seria possível a realização de etnografias ou observações participantes - outros métodos são empregados. Nesse caso, a análise textual de produtos musicais mostra-se um recurso interessante, da mesma forma que a pesquisa de outras instâncias que possam auxiliar na compreensão do objeto. Do mesmo modo, a coleta de narrativas orais cotidianas de pessoas que vivenciaram a cena permite revelar aspectos importantes do fenômeno. A interpretação de vestígios como artes gráficas, fotografias, produtos audiovisuais e informações disponíveis em material hemerográfico, que podem ser acessados em arquivos e bibliotecas, centros de documentação de jornais ou no acervo de algum colecionador ou amante do período em questão, podem servir ainda como contextualização das práticas musicais, e foram esses os recursos metodológicos de pesquisa acionados nesta pesquisa.

De maneira geral, há uma utilização frequente de métodos de pesquisa oriundos de campos como a etnomusicologia, a música, a história, a 
antropologia. Podem-se destacar pesquisas em comunicação da área de scene research que fizeram uso dessas ferramentas metodológicas, como Jacques (2007), que aborda o rock independente de Florianópolis, Fernandes (2007), cujo trabalho recai sobre a cena indie carioca, e Amaral (2009), que propõe uma etnografia da cena tecnobrega de Belém do Pará. A etnografia dá conta da descrição de eventos desencadeados no momento da observação, e o trabalho de campo pressupõe o contato direto entre entrevistador e entrevistado. No caso dos autores de comunicação que se utilizam desses métodos, no entanto, convém buscar algum diferencial ou especificidade em suas contribuições, a fim de enfatizar uma observação mais aprofundada sobre a ação dos diversos processos comunicacionais na análise das cenas musicais. Obviamente, diante da consolidação cada vez maior de uma prática multidisciplinar para os estudos sobre a cultura, é interessante que haja sempre um diálogo e intercruzamento de teorias, conceitos e práticas que podem se complementar e dar conta das múltiplas faces de um dado objeto de estudo. Mas aspectos comunicativos não devem ser isolados ou negligenciados.

Em nosso trabalho, a realização de entrevistas e pesquisa de materiais publicados à época em que o fenômeno se desencadeou mostra-se eficaz no sentido de reconstruir narrativas, compreender discursos de valor e gosto e perceber lógicas de formação de alianças e configuração de experiências subjetivas anteriores ao momento da pesquisa. Optei pela realização de algumas entrevistas abertas, que foram elaboradas com a finalidade de explorar impressões a partir de perguntas amplas, em que os entrevistados tinham liberdade para desenvolver aspectos e discorrer sobre fatos que fossem mais interessantes. A partir de diálogos informais, foi possível explicitar algum detalhe ou preencher lacunas sobre fatos específicos, captando nuances e comentários espontâneos. A opção por esse formato de entrevista pareceu o mais apropriado para a investigação de aspectos afetivos e valorativos dos informantes que participaram dessa cena musical, o que permitiu conhecer alguns significados pessoais, motivações, atitudes e comportamentos.

Minha proposta foi recuperar, mesmo que parcialmente, uma temporalidade e uma experiência conforme foi concebida pelos que vivenciaram a cena, suprimindo lacunas no processo de reconstituição histórica. Foi importante, para essa etapa, recorrer à documentação primária - correspondências, 
relatos e depoimentos públicos, registros institucionais, periódicos - e a fontes secundárias - escritos não contemporâneos aos fatos narrados, como textos acadêmicos, jornalísticos, literários e ainda comentários em blogs e sites de redes sociais. No que tange à pesquisa e ao resgate da experiência musical em contextos passados e/ou residuais, a pesquisa histórica permitiu lançar mão de informações presentes em documentos textuais, incluindo livros, fanzines, sites de internet e material hemerográfico tradicional. Também há a análise de documentos audiovisuais, como filmes, gravações caseiras, programas de TV, documentários, videoclipes e registros de apresentações ao vivo, que são utilizados como importantes fontes para enriquecer o entorno contextual, conferindo um maior aprofundamento à pesquisa empreendida. A análise textual ainda aparece como uma alternativa para oferecer pistas no processo de apreensão das cenas.

Como forma de inferir considerações a respeito da cena manguebeat em Recife na década de 1990, Lima (2007) analisou alguns discos específicos e canônicos dos grupos Mundo Livre S/A e Chico Science \& Nação Zumbi, levando em consideração as noções de performance e música popular massiva. Já Ribeiro (2006) utilizou referências encontradas em filmes como Blade Runner (1982) e obras literárias de ficção, em sua maior parte, da chamada ficção científica, como forma de construir uma narrativa historiográfica da referida cena mangue. Nesse caso, a literatura constituiu um dos elementos basilares do universo musical manguebeat, fundamental para o arcabouço das estruturas de sentimento da cena no que diz respeito à partilha de experiências, gostos e afetos comuns inscritos em dado território musical. (RIBEIRO, 2006, p. 33)

Tentei compreender como se dava a projeção de desejos e valores materializados em situações cotidianas e produtos musicais específicos relativos à cena musical da Black Rio. Esse método foi assumido como forma de mapear os sentidos que emergiram a partir dos bailes soul, observando também como possíveis expectativas foram geradas por seus participantes. Nesse sentido, tento perceber como se estabeleceram experiências estéticas que transformaram sensibilidades e moldaram afetos, da mesma forma que configuraram novas convenções, códigos e repertórios, cujos indícios ainda permanecem sendo reatualizados no presente. Nossa proposta, pois, se deu no sentido de 
desenvolver uma genealogia do movimento Black Rio, em uma espécie de história social dos processos comunicativos engendrados no interior e a partir da cena, a partir dessa experiência coletiva. Essa leitura parte de uma negociação com diferentes horizontes temporais, incorporando tanto interpretações atuais quanto questões que emergiram na época do seu desdobramento, como forma de interpretar as práticas acionadas pelos atores sem perder de vista possíveis sensibilidades cultivadas à época.

Ao propor esse estudo diacrônico, na apreensão de seus aspectos sensíveis, opto por interpretar os produtos da cultura popular massiva que se relacionavam à cena Black Soul, como filmes, discos, fotografias, panfletos e ainda publicações que circularam na época. A ideia é descrever a atmosfera sensível que emergiu dessa cena musical como forma de revelar aspectos da experiência em suas dimensões estéticas, históricas e comunicativas. Da mesma forma, debrucei-me sobre o conjunto de comentários críticos sobre a cena, entendendo esses discursos como reveladores das visões sociais e julgamentos de valor que são confrontados com reflexões atuais sobre dinâmicas identitárias e ideologias políticas, especialmente relativas à trajetória do movimento negro brasileiro. A partir desses vestígios selecionados, tento compreender como se articulou a cena musical aqui estudada e como ela originou um tipo de estilo que definiu novos parâmetros subjetivos e novos exercícios políticos e culturais, especialmente em um momento de polarizações e tensões na arena pública brasileira.

Para lidar com esses resquícios, Koselleck (2006) sugere a aplicação de duas categorias meta-históricas: o espaço de experiências e o horizonte de expectativas. O espaço de experiência se relaciona ao local da memória, às recordações, que remeteriam ao passado, localizados em um dado território simbólico - os bailes, o subúrbio, as ruas. Na experiência, fundem-se tanto elaborações racionais, discursivas, quanto comportamentos e ações cotidianas no âmbito individual e coletivo, "o que nos leva a crer que tanto em documentos institucionais (como livros acadêmicos e matérias de jornais) quanto nas narrativas subjetivas [...] podemos ter acesso a esse espaço de experiências impessoal”. (CARDOSO FILHO; OLIVEIRA, 2013, p. 12) Já o horizonte de expectativa, em sua dimensão pessoal e interpessoal, corresponde a projeções, previsões, desejos e também análises racionais do presente sobre 
algo que já aconteceu, e ainda sobre o que está por vir. Narrativas pessoais e produtos culturais massivos podem compor vestígios das experiências, dando conta das potencialidades estéticas e políticas que compuseram o repertório da cena musical e que abriram espaço para rupturas, inovações criativas e novas visões de mundo.

As experiências e expectativas podem ser modificadas com o tempo, e o confronto dessas duas instâncias permite desconstruir discursos que pretendam abordar "a realidade" ou "a verdade" sobre um objeto cultural, abrindo o olhar do pesquisador para perceber tensões, ambivalências e nuances que envolvem todo fenômeno cultural. Na captura dos vestígios da experiência da cena soul, as ações de consumo cultural e os estilos criados por seus participantes pressupunham modos específicos de organizar estrategicamente o tempo na construção reflexiva da autoidentidade. Nessa construção subjetiva, as projeções e desejos se voltavam para o futuro, mas também se baseavam em reinterpretações do passado, retrabalhando tradições e permitindo que os blacks dialogassem dinamicamente com diferentes temporalidades.

Assim, os estilos em jogo na cena da Black Rio deslocavam sua fixidez enquanto banco de "reserva" de significados, sentidos e práticas sociais. A observação dessa paisagem conduz o olhar para uma série de manifestações culturais e subjetivas, cujas estruturas serviam como base para a difusão musical, congregando agentes de suporte e de sustentação, ao mesmo tempo em que ofereciam um local de memórias e insights sobre a vida urbana na experiência da partilha da música. (GUERRA, 2011) Um espaço-problema alterado ao longo do tempo, reconfigurado a cada momento por seus participantes, que ampliavam e deslocavam os significados da cena.

Por conta dessa característica movente, os procedimentos metodológicos a serem adotados no estudo das cenas precisam dar conta da multiplicidade de tensionamentos e fissuras possíveis que podem ser instauradas tanto pela ação dos sujeitos quanto pela força situacional do contexto. Uma cena musical tem inclusive a capacidade de reorganizar as histórias e narrativas de sua gênese, criando novas alterações e fissuras (CARDOSO FILHO; OLIVEIRA, 2013), visto que as relações, representações e processos sociais apropriados por indivíduos não são transparentes. Eles estão envoltos em um senso comum que, simultaneamente, os valida e os mistifica. (HEBDIGE, 1979, p. 13) 
Por isso, os objetos culturais percebidos e aceitos como elementos detentores de um valor semiótico em um sistema de comunicação governado por regras semânticas possibilitam o acesso a códigos e discursos apreendidos tanto na experiência quanto na significação, marcadas por opacidades e ambivalências na produção de representações e dimensões ideológicas.

Observar as cenas com base em suportes midiáticos como discos, espaços, shows, publicações especializadas, bem como na forma como se dão os usos sociais dos produtos culturais por meio dos estilos, é uma forma de penetrar em uma economia de um imaginário coletivo (MARTÍN-BARBERO, 2008, p. 160), em que os processos comunicativos se estabelecem nos fluxos de impressões sensíveis e experiências subjetivas que permitem identificar modos de elaboração, tensionamentos e expectativas estabelecidas por diversas narrativas entrelaçadas. Por meio dessas narrativas, é possível perceber como discursos dos atores envolvidos - fãs, produtores, DJs, músicos, críticos - podem estar articulados à configuração dos gêneros musicais em torno dos quais se estrutura a cena. A própria materialidade da cena é dada pela ação comunicativa, apresentada em artefatos como discos, ilustrações, ingressos, banners, cartazes, fotos, fanzines e outros tipos de publicações alternativas produzidas por integrantes, usados como suporte para a circulação de valores, signos e códigos presentes dentro daquele contexto. Da mesma forma, os estilos que se desenvolvem no interior e para além das cenas é um fator fundamental a ser observado na compreensão do fenômeno. Os estilos engendrados nas cenas musicais possuem um grande potencial transformador e um poder político intenso, apresentando diferentes formas de construção da cidadania e estratégias de ocupação de um espaço público, oferecendo novas maneiras de existência social através do consumo da música.

\section{Os estilos em cena}

Na configuração dos estilos, os objetos mundanos possuem função principal e podem se converter em materiais simbólicos ao assumirem uma ação de subversão de ordens, instituições e fronteiras, assinalando e reorientando a presença da diferença. Os objetos também jogam com estigmas e são uma porta de entrada para a construção de sentimentos de pertencimento a uma 
comunidade alternativa. $\mathrm{O}$ estilo condensado nesses artefatos cria um inventário simbólico na definição de um ethos particular. A adoção de um estilo de vida implica escolhas estratégicas dentro de uma pluralidade de opções possíveis, rotinizando práticas e hábitos em termos de vestimentas, modos de agir, frequência em locais de encontro. Os estilos estão constantemente abertos a mudanças de acordo com a natureza móvel das identidades. "Além disso, a seleção ou criação de estilos de vida é influenciada por pressões de grupo e pela visibilidade de modelos, assim como pelas circunstâncias socioeconômicas" (GIDDENS, 2002, p. 81), reproduzidos e reelaborados diante de apropriações e de agenciamentos determinados nas relações com a sociedade e com o mercado.

Essa perspectiva segue proposição de Hebdige (1979) em seu estudo sobre as subculturas de teddy boys, mods, rockers, skinheads e punks. Por meio do estilo, esses grupamentos juvenis exibiam ao mundo suas presenças e desvios, utilizando determinados objetos cujo uso simbólico materializava marcas identitárias de valor contra-hegemônico, como cabelos, roupas, adereços e tatuagens. Hebdige dava prosseguimento às pesquisas desenvolvidas pelos teóricos do Centre for Contemporary Cultural Studies da Universidade de Birmingham, na Inglaterra, que pretendiam uma abordagem interdisciplinar para investigar estilos e atividades de diversos grupos juvenis no período pós-Segunda Guerra Mundial. Ao lado de obras como Resistance through rituals, de Stuart Hall e Tony Jefferson, de 1976, e Profane culture, de Paul Willis, de 1978, Hebdige figura com seu Subculture: the meaning of style (1979). Esse conjunto de textos tinha um claro objetivo de legitimar os modos de vida das subculturas juvenis por meio de análises textuais e trabalhos de campo etnográficos.

No estudo das subculturas, havia uma preocupação central em compreender como artefatos e práticas culturais específicas eram capazes de promover a aceitação de um status quo e dominação social ou de incentivar determinados grupos juvenis subordinados a resistir à opressão e a contestar estruturas de poder conservadoras. Assim, as subculturas consolidavam estilos emergentes que, mesmo pautados por hábitos de consumo e indústrias do lazer, também sinalizariam mais profundamente como respostas alternativas das culturas juvenis. Nesse sentido, os estudos subculturais pretendiam 
ir além de inventários de padrões de consumo, a fim de avaliar a função do uso criativo e espetacular dos artefatos da cultura de consumo como forma de desafiar instituições hegemônicas da sociedade.

No entanto, nos anos 1990, uma série de críticas foi elaborada em relação ao conceito de subculturas juvenis, especialmente diante da profusão de estilos, práticas, gêneros musicais efêmeros e também diante da grande oferta de artefatos de consumo, responsáveis pela volatilidade e hibridação constante das formações culturais no espaço urbano. Basicamente, as críticas incidiam sobre alguns aspectos, como o fato de que os pressupostos das subculturas não davam conta apropriadamente de temas como gênero e raça, privilegiando a centralidade das condições de classe na definição dos estilos subculturais. Outra corrente criticava a visão elitista sobre processos de consumo cultural por parte da juventude excluída da análise subcultural, vista como conformista ou passiva. Alguns autores também denunciavam a ênfase no estilo visual, deixando de lado aspectos relativos ao consumo musical, bem como a persistência de uma visão romantizada sobre a capacidade de resistência e o poder político das subculturas. ${ }^{3}$

Outra crítica que se pode fazer aos estudos subculturais é em relação à sua visão datada e bastante específica sobre um modelo de juventude - enquanto categoria sociológica -, de certa forma, bastante ocidentalizado e idealizado, cujos símbolos estariam presentes em um tipo específico de cinema comercial e em um formato de produção musical massiva. Essa juventude dizia respeito a um contexto social bastante específico, não sendo um modelo aplicável a outros cenários, épocas e sociedades. A visão subcultural do jovem baseada em uma suposta rejeição ao mundo adulto e à civilização burguesa, ainda que compreendesse o consumo como instrumento estético e lúdico para a fruição individualista e capitalista, em uma perspectiva ambivalente, mantinha resquícios de visões utópicas de vanguardas artísticas e de movimentos libertários, como o de maio de 1968, marcado pelo existencialismo do pós-guerra. A noção de juventude como algo homogêneo efetivamente vem sendo desarticulada desde então, diante de complexos fatores

3 Para uma revisão da crítica a respeito das subculturas, ver: Freire Filho e Fernandes (2005). 
sociológicos, demográficos e produtivos que têm tornado a "condição juvenil" cada vez menos estável e fluida.

Se a noção de subcultura como aporte teórico para a compreensão da relação entre jovens, músicas e identidades mostra-se, assim, insuficiente, creio que a proposta da noção de cena musical parece mais adequada por dar conta dos processos e fluxos globais e rearranjos locais híbridos em torno do consumo musical, mostrando-se também suficiente para a compreensão de afiliações e laços de afeto materializados sobre um dado espaço urbano, articulando o consumo a um potencial de crítica cultural. No entanto, parece-me ser ainda potente a relação entre consumo cultural e configuração de estilos no que diz respeito à performatização de gostos e de identidades que envolvem uma leitura diferenciada dos artefatos simbólicos que estabelecem novas sociabilidades.

Os estilos são, nesse sentido, respostas mediadas, como aponta Hebdige (1979, p. 80), conformadas em torno do gosto e da circulação da música, em que participantes das cenas musicais dramatizam, performatizam e constroem uma linguagem própria que demarca seus cotidianos e suas práticas culturais. Os estilos construídos dentro e a partir das cenas podem refletir fragmentações, ambiguidades e tensões cujas posições se alternam em jogos reflexivos e complexos. Como práticas significantes e codificadas, eles são compostos por elementos como música, iconografia visual, performances, roupas, estéticas e sistemas de valores (HEBDIGE, 1979), partilhados coletivamente, que se manifestam na configuração de processos identitários diferenciados. Essas estratégias que entrelaçam estética, performance, linguagem, sonoridades e discursos (OLIVEIRA, 2015b) implicam formas de negociação de posições, acionando diversas representações que estabelecem diálogos entre processos de subjetivação e condições de existência material, que dividem um mesmo tipo de linguagem e práticas significativas. Em relação aos estilos, Facchini (2011) ainda propõe uma articulação mais profunda entre estilos e performances como deslocamentos a partir de uma dramatização social.

Gostaria de argumentar, ainda, que os estilos não são produzidos por sujeitos pré-dados que agem de forma inteiramente consciente 
em relação aos efeitos a serem provocados pelas mensagens comunicadas por dada composição de aparência, atitude e música, mas que os sujeitos são constituídos no processo de citar e deslocar normas sociais, e isso pode se dar no processo de composição ou de encenação de determinado(s) drama(s) por meio do estilo. (FACCHINI, 2011, p. 146)

As cenas provocam, assim, a conformação de novos estilos em torno de um determinado território significativo. Nas roupas, no linguajar, na performance cotidiana ou acionada apenas durante a noite, o show, o baile, é possível perceber o engajamento dos estilos nas performances de gosto. Em seu texto "Pragmáticas do gosto", Hennion (2011) argumenta que o gosto é performatizado por meio de diferentes formas de vinculação, que envolvem dispositivos como tempo, espaço, regras e rituais, objetos e afetos, bem como o corpo e suas experimentações dentro de um cenário constituído a partir das condições midiáticas da configuração dos gêneros musicais. O corpo, particularmente, assume centralidade no estilo, por meio da aparência e da expressão de um controle e de uma construção ativa de uma imagem. Os estilos também implicam um gesto baseado na experiência sensível e provisória da vivência em um determinado espaço e nas sensibilidades e sensações despertadas a partir da escuta musical. Na materialização das performances de gosto, os estilos funcionam, pois, como rituais para a marcação da diferença, que enfatizam o caráter pragmático e performativo das práticas culturais, colocando em evidência a capacidade dos participantes de uma cena musical de transformar e criar novas sensibilidades. É Giddens (2002, p. 79) quem aponta a relação entre estilos e subjetividades, compreendidos como um "conjunto mais ou menos integrado de práticas que um indivíduo abraça, não só porque essas práticas preenchem necessidades utilitárias, mas porque dão forma material a uma narrativa particular da autoidentidade”.

Nesse sentido, o gosto seria uma modalidade problemática de conexão e engajamento no mundo, como uma atividade reflexiva, corporificada, enquadrada coletivamente, que produz simultaneamente competências e repertórios de juízos de valor. A natureza performativa do gosto e do estilo diz respeito, de tal modo, a estruturas coletivas, a materiais discursivos, à acumulação de sensações e à coleção de gestos derivados do ato da escuta e 
da fruição musical. Sua formação reflexiva se refere ao fato de que o gosto é formado no momento em que é expresso, e ele é expresso ao mesmo tempo em que se configura como uma espécie de tecnologia de apresentação de si. (HENNION, 2011, p. 263) O gosto ainda condiciona e é condicionado por signos sociais, por diversas origens históricas e culturais, por pretextos contextuais e rituais de prazer e felicidade que se articulam ao estilo, demarcando individualidades e formas de autoexpressão a partir daquilo que Herschmann (2000, p. 63) chama de uma "consciência de si estilizada".

É interessante pensarmos que, como disposições de identificação, os estilos formulados a partir dos gostos não são constituídos em cima de ações conscientes ou deliberadas. Eles surgem em meio a um conjunto de diversas formas de engajamento corporal não mecânicas, mas tampouco são naturais. Nesses atos performáticos cotidianos e repetitivos, há um condicionamento do gosto e um engajamento do corpo como uma construção social, submetida a normas e dispositivos culturais. As performatizações de gosto, assim, são atos reflexivos, pois imprimem marcas no corpo, que se constroem socialmente mediante interações extensivas com os objetos - no caso, musicais - e nas reiterações de gestos cotidianos que passam a ser internalizados e manifestos na apresentação pública dos estilos. Esses corpos, envoltos pelo estilo, são capazes de absorver sentidos e afetos pelo uso de objetos culturais, se mostrando habilitados para reconhecer o que outros corpos reconhecem (HENNION, 2011), compartilhando sensibilidades e identidades.

Na compreensão desse processo de compartilhamento de afetos, também é possível recorrer a Rancière (2005), cujo conceito de "partilha do sensível" é retomado por Janotti Junior (2012a) na compreensão da indissociabilidade entre estética e política no interior das cenas musicais. Na interpretação do sentido das cenas, os estilos, enquanto práticas significativas, se desenvolvem a partir da experiência coletiva do contato com a música, revelando processos de produção e recepção de afetos e significados, ampliando competências tanto pragmáticas quanto performativas. Eles são acionados no momento da interação, enquanto experiências estéticas, e confirmados na experiência cotidiana, enquanto proposição política. Pois é na "partilha do sensível", presente no cerne da própria ideia de cena, que há um compartilhamento de algo que é comum - a música, o espaço, a experiência, a escuta - de forma tensiva, 
que pressupõe uma participação, mas, ao mesmo tempo, uma individualização dentro daquela comunidade.

Giddens (2002, p. 81) entende que os estilos de vida se referem também à convergência e à pluralização de escolhas que dizem respeito aos domínios público e privado, e essas articulações estão caracteristicamente ligadas a ambientes específicos de ação - que podemos entender aqui como as cenas musicais. Os estilos expressam as cenas de onde se originam e suas configurações, muitas vezes, se referem a decisões dos participantes de se aprofundar nesses ambientes, materializando nos corpos, nos hábitos, na roupa e na performance nuances da cena conjugadas com suas próprias identidades. Se os estilos se referem a modos estratégicos de ação, eles podem ser modificados quando adotados em diferentes contextos e espaços. Mas mantêm uma razoável regularidade em seus modos de ação dentro de um grupo de práticas relativamente consistentes, que são ordenadas e encenadas em alguns momentos em contraste a outros momentos da vida diária. As cenas musicais, pois, oferecem um lugar seguro para a ancoragem de estilos de vida, especialmente ligados a padrões de consumo e comportamentos juvenis, conformando suas ações e encenações simbólicas.

Os estilos são também acessíveis a grupos menos privilegiados que passam a vivenciar realidades permeadas pelos componentes institucionais de uma suposta modernidade ocidental. Mesmo em situação de privação econômica e exclusão, os estilos adotados se mostram como maneiras diferentes de elaboração de sobrevivências e configurações reflexivas identitárias, afetadas pela globalização. Diante da mundialização, ampliam-se as alternativas de identificação, ocupando espaços em branco deixados pela tradição.

Essa justaposição se confirma na existência de um comum e de partes desse comum que estabelecem lugares e identidades culturais singulares, mas que compartilham espaços, tempos e ações que se retroalimentam dentro desse ciclo de partilha. Assim, esse modo simultâneo de dividir e compartilhar a experiência sensível comum é alocado à conjugação da política com estética, especialmente porque são os diferentes tipos de percepção que geram divisões e fronteiras em uma determinada realidade social. As cenas, dessa forma, proporcionam a inserção de novos atores na realidade das cidades e oferecem um local para a promoção de novas ações políticas e arranjos 
identitários que oferecem diferentes visões sobre o mundo, ao mesmo tempo que possibilitam novas formulações coletivas de visibilidade e existência social. Ao articular a ideia de estilo à proposição de uma espécie de cartografia social na configuração das cenas musicais, enfatizo o lugar da performance como manifestação móvel e deslizante das identidades em dados espaços e temporalidades, de acordo com as dinâmicas da experiência.

Tanto os estilos quanto as cenas musicais são ferramentas conceituais importantes que nos dão a oportunidade de apreender as atividades e exercícios subjetivos que se desenvolvem em torno da Black Rio, englobando desde instâncias produtivas à ação dos consumidores, permitindo a compreensão de seus significados para os sujeitos envolvidos. A cena da Black Rio, assim, pode ser descrita como uma atividade cultural que revelou dinâmicas sociais que se articulavam ao próprio processo histórico e social de urbanização da cidade do Rio de Janeiro. Nessa trajetória, políticas alternativas de estilo e atividades de entretenimento popular, especialmente no que se refere às populações negras, ajudaram a moldar o território dentro do qual essa cena musical se configurou, diante de ações criativas e marginais centrais para a criação de um senso coletivo de identidade. Para a interpretação da Black Rio, no próximo capítulo, enfocarei a descrição de contextos culturais e sociais que antecederam essa cena, como forma de compreender as condições prévias para a sua emergência, articulando essa cena a um longo trajeto de hábitos e costumes ligados ao lazer popular e à penetração de novos gêneros musicais na vida social da cidade. 